
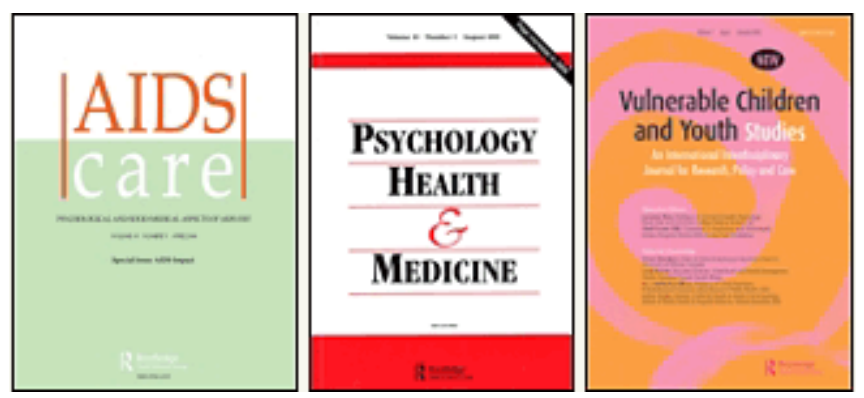

\title{
Is HIV testing normal or special? Opinions of health professionals in four European countries in 2008.
}

\begin{tabular}{|r|l|}
\hline Journal: & $\begin{array}{l}\text { AIDS Care-Psychology, Health \& Medicine - Vulnerable Children } \\
\text { and Youth Studies }\end{array}$ \\
\hline Manuscript ID: & AC-2010-11-0635.R1 \\
\hline Journal Selection: & AIDS Care \\
\hline Keywords: & $\begin{array}{l}\text { HIV testing, pre-test counseling, health professionals, patient } \\
\text { choice, Europe }\end{array}$ \\
\hline
\end{tabular}

\section{SCHOLARONE ${ }^{\text {m }}$ Manuscripts}




\section{Is HIV testing normal or special? Opinions of health professionals in four European countries in 2008.}

\section{Abstract}

The special norms in testing for HIV infection are not typical of testing or screening for other diseases. In four European countries, we studied health professionals' views on HIV testing. This study is based on cross-sectional surveys of two groups of health professionals: presidents of selected health professional societies and head physicians and nurses of selected hospital clinics in Belgium, Estonia, Finland and Portugal in 2008. A common structured semi-anonymous questionnaire was used in the four countries. The number of societies responding varied from 5-10 and for hospital clinics from 6-18; the response rates were from $32-100 \%$ and $41-100 \%$, respectively.

Opinions on whether HIV testing is like any other test and on the value of specific approaches in HIV testing varied both within and between countries. Some professionals thought that HIV testing is different from the testing of other infectious diseases; others thought that such an exceptional approach may be a disservice to people and to the health system. Many professionals thought that HIV testing should not be thought of only from the point of view of the individual to be tested, but also from that of other people (potential patients). Obligatory testing was considered appropriate in certain circumstances. Generally, more HIV testing in health care was called for.

Normalization of HIV testing, i.e. considering it like any other diagnostic test, is unlikely to meet much opposition from health professionals. Larger surveys are needed to confirm the results.

\section{Key-words.}

HIV testing, voluntary, pre-test counseling, health professionals, patient choice, Europe, survey 


\section{Introduction}

In Europe geographical and group-differences in HIV infection rates and treated patients are large (WHO, 2009, UNAIDS 2010). The role of screening and testing, both as a method to identify people for treatment and to prevent the spread of HIV infection, has been controversial. At the early stage of the HIV epidemic, inability to do much and the stigma attached to the disease created special norms in testing and a strategy called HIV/AIDS exceptionalism emerged (Bayer, 2001; de Cock and Johnson, 1998). Providing thorough information before testing and informed consent or anonymous testing are not customary in testing and screening for other diseases.

HIV testing in Europe is generally voluntary, except for blood and organ donors. There is no universal testing, but testing is often recommended for patients with tuberculosis or sexually transmitted diseases, pregnant women, persons in high risk groups, and prisoners (Mounier, Nielsen and Coker, 2008; Deblonde et al., unpublished manuscript). Even though there is a large body of literature on HIV testing, only a few empirical studies on health professionals views from Europe exist (Deblonde et al., 2010) with most coming from North America (Burke et al., 2007; Arbelaez et al., 2009). There are no previous studies that compare different countries.

As a part of a project on HIV testing practices in European countries (Assessment of HIV testing in Europe, 2010, Deblonde et al., unpublished manuscript) we studied health professionals' views on HIV testing in four countries representing different health care systems, HIV epidemic and social circumstances: Belgium, Estonia, Finland, and Portugal. The purpose of this sub-study was to find out health professionals' views on: whether HIV testing is similar to other disease testing, whether the special requirements are an obstacle to testing, the connection between individual interests and the public good (other patients' interests) and whether HIV testing should be encouraged more. 


\section{Methods}

This study is based on a cross-sectional survey of two groups of health professionals in four European countries using a common questionnaire, run in the summer and early autumn of 2008. Professionals were recruited from clinics serving HIV patients and from presidents of professional societies.

Society survey. The researchers made a model list of professional societies including societies from the eleven disciplines: general practice, infectious disease, sexually transmitted infections (STI), skin-STI (dermatology-venerology), obstetrics and gynecology, lung disease/tuberculosis, occupational health, surgery, (public health) nurses, midwives, AIDS nurses. Not all countries had societies in these disciplines or they had more than one. It was up to the local researcher to compile a list close to the model list. Presidents (or a person they designated) were asked to complete the questionnaire

Clinic survey. Public hospitals likely to see HIV patients were selected. The original plan was to select the head physician and nurse of three outpatient clinics (infectious disease, emergency, internal medicine). However, health care for HIV patients was organized differently in the four countries; some countries also included outpatient clinics in obstetrics and gynecology, tuberculosis, STI, and specific HIV/AIDS clinics.

The presidents or their secretaries and the head physicians and nurses were approached with various ways: e-mail (Belgium, Estonia, Portugal), ordinary mail (Belgium, Finland) and by fax (Portugal). 
They were informed and reminded by the same methods and by phone. The numbers of professionals approached and the response rates are given in Table 1.

Questionnaires. Both surveys used a structured questionnaire containing questions on HIV testing, focusing on potential barriers. The same questions were used in the two surveys, but the questionnaire for clinics contained additional questions. We use the term "testing" to include both screening (systematic testing of a population or a subgroup of population) and diagnosis (done on the basis of symptoms or other suspicion). Confidentiality refers to the duty of the health care provider not to disclose a person's HIV/AIDS status. Anonymous testing refers to results being recorded without revealing the person's name. The main questions used in this study are given as an Appendix. The questionnaires were semi-anonymous, i.e. they contained the name of the society or clinic, but not the respondents' name.

The final English draft of professional societies was piloted by two Finnish physicians active in professional societies. The English master copy was translated into Dutch and Finnish by researchers and into Estonian and French by professional translators; in Portugal the English version was used. A cover letter in English was composed and the local researchers modified it to correspond to local traditions and requirements.

Analysis. Data entry using Epi-Info and Excel was made in each country using a joint data-entry template with coding instructions composed in Finland. The analyses were made by SPSS and Excel statistical packages. The main aim was to study the overall views and consistency of the opinions. Due to the small number of respondents and somewhat different target groups and response rates descriptive tables with raw numbers have been used. 
Ethics committees. The whole study was approved by the Ethical Committee of the University Hospital Ghent, Belgium (Belgian registration number B 67020084034). No further ethics committees in other countries handled the surveys (not customary for anonymous surveys of health professionals).

\section{Results}

Most respondents were physicians (Table 2), with the rest being mainly nurses. Most had extensive professional experience, but not all presidents had worked with HIV patients. When the presidents were asked what kind of role their society should have in relation to HIV, some respondents in Belgium ( $n=1)$, Estonia ( $n=2)$ and Finland $(n=3)$ said that HIV related matters were not a focus of their society. Some societies had participated in the formulation of policy or national guidelines.

\section{Is HIV testing like any other testing?}

When asked whether HIV testing is like any other test, opinions varied both between the countries and the two groups (Table 3). In Belgium most respondents (20 of 26) said that it is different from other tests and should require special procedures, such as pre-test counseling and explicit informed consent. In Finland most respondents (14 of 16) said it is like any other test. In the other countries the opinions were relatively evenly distributed between these options.

Two other questions indirectly measured the normality of HIV testing. When asked about measures to ensure that HIV infected people are tested early (Question 21, Appendix), some professionals, especially in Finland, had selected in their top three the following measures: "HIV-testing should be done routinely like any other test" and "eliminate the pre-testing counseling". In a question on 
professionals' views of the main barriers to health care providers offering HIV testing (Question 11), some chose the option that pre-test counseling is a barrier (Table 3).

The respondents were asked the society's opinions or the clinic practice's in regard to opt-out and opt-in ways to offer HIV tests (for definitions, see Question 8 and Table 3). Many presidents, especially in Belgium and Finland said that the issue has not been discussed within their society or they did not know the society's view. Of those who knew their society's view, Finnish (2 of 2) and Portuguese ( 3 of 4 ) presidents most commonly chose the alternatives of opt-out or assumed consent (Table 3). Belgian and Estonian presidents most commonly reported that the opt-in alternative was supported by the society. In Belgian (6 out of 11), Finnish (3 out of 5) and Portuguese (10 out of 13) clinics, opt-out and assumed consent were common practices.

\section{One patient or all (future) patients.}

Whether HIV testing should be thought of from the point of view of the individual to be tested or also from that of other people (potential patients) was not directly asked, but it was measured indirectly with two questions (Table 4). The professionals were asked to choose which three alternatives from the several given were the least performing areas in their HIV health care system and in most need of improvement in their own country (Question 13). In all countries most respondents thought that prevention of epidemic (information and education, condoms, clean needles etc.) needed further attention. Table 4 contrasts this opinion against two more individualfocused aspects of HIV health care - access to HIV drugs and social and psychological supportwhich were chosen far less often as being most in need of improvement. 
The professionals were asked whether there are situations when HIV testing should be required (Question 20). Very few respondents thought that a HIV test should never be obligatory. Most presidents supported the claim that a HIV test should be required during pregnancy (apparently thinking of the unborn child). With the exception of the Finnish presidents, obligatory testing in other medical situations to prevent the spread of HIV infection was not widely supported. Requiring testing to obtain a visa to enter the country received little support (Table 4).

\section{Encouragement of HIV testing.}

Several questions asked the professionals for their views on whether the current extent of HIV testing should be expanded. Generally, more HIV testing was favored. When asked about the areas in the HIV health care system in their country that did not perform so well (Question 13), a third put "not enough testing among the general population" (29 of 86) or "among risk groups" (29 of 86) in the top three most important areas (Table 5). When asked for the best ways to ensure that HIV infected people are tested early (14 alternatives, Question 21 Appendix), more than a third (34 of 86) of respondents chose "offering a HIV test to all patients in health care" and about half (43 of 86) "offering it to specific groups of patients" (Table 5).

The professionals were asked what would likely follow from offering HIV testing to all patients visiting health care. Many (75\%) thought that as a result most HIV infections would be found early enough and that it would lessen the stigma attached to HIV (52\%). However, various alternatives specifying concerns were also chosen, including: weakened possibilities to give pre-test counseling properly (36\% of respondents), putting people off visiting health care for fear of a positive HIV diagnosis (21\%) and time and money being taken from other more important tasks (18\%). 
Most respondents saw missed opportunities to diagnose HIV infection in health care settings and felt that health care providers should offer HIV tests more actively (Table 5). About half were of the opinion that HIV testing should be encouraged outside health care, for example, through outreach programs. Somewhat less thought that self-testing should be (more) available in their country (Table 5).

\section{Discussion}

Our survey showed variation both within and between countries in the health professionals' opinions of the value of the special features of HIV testing. Our sample size was too small to compare in detail the variation between different groups. But the consistency of results suggests that there may be real country differences, worthy of further studies. Some professionals thought that HIV testing is different to testing for other infectious diseases, but almost half chose the option that it is like any other test. Many professionals identified these special requirements as potential obstacles to testing.

Anonymous testing is a special feature of HIV testing (Deblonde et al., unpublished manuscript). We did not directly ask about anonymous testing, but asked about testing outside of health care and self-testing, which often are anonymous. Many physicians supported testing outside health care and self-testing. However, the questions were in the context of how to encourage testing, and the results may overestimate the real support for anonymous testing.

The health professionals wanted more HIV testing and thought opportunities for such were missed in health care and about a third supported testing of all patients who visit health care. However, 
testing was not considered the highest priority in tackling the HIV epidemic, with that position being given to primary prevention methods.

\section{Strength and weaknesses}

Cross-country comparisons are important as they bring more variation to the context and allow for identifying issues that are common medical thinking. However, carrying out a comparative survey of health professionals' opinions on HIV screening is particularly challenging in such varying contexts. To find comparable groups we chose the presidents of various professional societies as we felt that professional societies were relatively similarly organized in the study countires. Furthermore, the presidents of professional societies are often leading professionals in their country, and their opinions may predict future practices. To garner the opinion of health professionals who have expert knowledge of HIV patients, we chose physicians and nurses in clinics treating HIV patients. However, the variation in service provision meant the groups were not particularly comparable between countries.

In previous surveys of physicians, response rates have been low and lower than in the general population (Kellerman and Herold, 2001). As an average, our response rate is good, but its variation between the countries and the two surveys limit between-group comparisons.

\section{Comparison to previous studies}

There are a number of surveys and other empirical studies among US physicians (Burke et al., 2007; Arbelaez et al., 2009) that focus on reasons why physicians do not do HIV testing. They have identified several modifiable barriers, including burdensome consent procedures and pre-test 
counseling requirements; these barriers also emerged in our study. Further barriers that are more difficult to change, such as lack of resources and of organized follow-up of positive cases, have been identified in US studies.

With the exception of four small British studies, we did not find previous empirical European studies on health practitioners' views on HIV testing (Kellock and Rogstad, 1998; Rogstad and Henton, 2004; Boyd, Simpson, Hart, Johnstone and Goldberg, 1999; Stokes, Mc Master and Ismail, 2007). None of these studies provided information related to the themes of our study.

\section{Existing recommendations}

In the USA, normalization of HIV testing is on the way. In 2006 the United States CDC (Centers for Diseases Control and Prevention) recommended routine testing of adults in all medical settings and an "opt-out" model (i.e. patients are informed that HIV testing will be performed unless they decline) (Burke et al., 2007). With the adoption of this model and with streamlined pre-test counseling, testing is likely to increase. Many states are moving from anonymous testing to confidential testing, while federal funding remains tied to name-based surveillance. However, opposition to normalization, particularly to abolishing pre-test counseling, has arisen (Koo, Begier, Henn, Sepkowitz and Kellerman, 2006). As pointed out by De Cock et al. (1998), normalizing HIV testing requires strong measures to be taken simultaneously to combat stigmatization and discrimination.

In 2007, the WHO/UNAIDS guidance on provider-initiated HIV testing recommended HIV testing for all patients whose clinical presentation might result from underlying HIV infection, irrespective of epidemic setting; furthermore it recommends routine testing in selected health facilities and in all 
medical care in generalized HIV epidemics (WHO/UNAIDS, 2007). It recommended simplified pre-test information instead of pre-test counselling and an opt-out principle in general. This suggestion has received support but also opposition (April, 2010).

The WHO Europe Policy Framework on HIV testing (WHO, 2010) does not recommend routine HIV testing in all health care settings, an exception being testing at-risk populations. No clear stand has been taken on whether to use pre-test information or pre-test counselling. In our survey (Deblonde et al. unpublished manuscript), the European countries varied by how much their policies emphasizing the special requirements of HIV testing. At national level, most country policies recommended the opt-in informed consent.

\section{Implications}

Much discussion has centered on the psychological effects of knowing that one is HIV positive and the social effects resulting from others knowing it. Since the introduction of effective treatments to postpone the AIDS phase and death, the burden of knowledge needs to be contrasted with the individual and collective benefits of knowing the HIV infection status. People who know they are HIV positive and who receive counseling are more likely to take precautions to protect their partners than people who do not know their serostatus (Marks, Grepaz, Senterfitt and Janssen, 2005). According to a study in the USA, people unaware of their HIV-positive status account for the majority of onward transmissions of HIV (Marks, Grepaz and Janssen, 2006).

The special features of HIV testing, informed consent with pre-counseling, and anonymous testing may have negative health impacts on the patient him/ herself and other people. Refusal of patients 
to be subjected to testing may stop them getting useful treatment and care. On the positive side, anonymous testing may encourage apprehensive patients to undertake testing.

No evidence exists to support the value of pre-test counseling for prevention (Koo et al., 2006). How testing provided without pre-test counseling (or simplified pre-test counseling) compares with testing with counseling is not known; there are also no studies comparing client- and providerinitiated testing or opt-in and opt-out approaches in regard to prevention and behavior change.

The current norm of pre-counseling with the option of refusing HIV testing sides with the infected patient rather than with other patients. Many physicians in our survey were not satisfied by this, suggesting that the good of other people (potential patients) should also be considered. The clearest example was the wide support for obligatory testing during pregnancy, apparently to protect the unborn.

The main argument behind the right to refuse HIV testing is the patient's right to self-determination - the right of the person to decide what is done to him or her in health care. However, in health care such a right is not typical for epidemic diseases. Also one could question whether the right to selfdetermination is equally important for diagnostic knowledge as compared to an intervention in one's body. In health education it is not uncommon to give information that a person may be unwilling to hear.

\section{Conclusions}

Our results suggest that the normalization of HIV testing (i.e. being just another diagnostic test) is unlikely to meet strong opposition from health professionals. Physicians supported more testing in 
health care. To achieve that, testing procedures should be simplified. Larger surveys that include a wide variety of physicians and more countries should be made to confirm the results of our small pilot survey.

\section{Acknowledgment}

The study is part of a study "Assessment of HIV testing in Europe: from policies to effectiveness", funded by a grant from the European Centre for Disease Prevention and Control (ECDC) - contract EDC.636: Opinions expressed are those of the Contractor only and do not represent the official position of the ECDC.

Conflict of interest: none declared 


\section{References}

1. Arbelaez C, Wright EA, Losina E et al. Emergency Provider Attitudes and Barriers to Universal HIV Testing in the Emergency Department. The Journal of Emergency Medicine 2009 Oct 13 doi:10.1016/j.jemermed.2009.07.038.

2. April MD. Rethinking HIV exceptionalism: the ethics of opt-out HIV testing in subSaharan Africa. Bulletin of the World Health Organization 2010;88:703-708.

3. Bayer R. Public health policy and the AIDS epidemic. An end to HIV exceptionalism? The New England Journal of Medicine 1991 May 23;324(21):1500_ 1504.

4. Boyd FM, Simpson WM, Hart GJ, Johnstone FD, Goldberg DJ. What do pregnant women think about HIV test? A qualitative study. AIDS Care 1999;11:21-29.

5. Burke RC, Sepkowitz KA, Bernstein KT et al. Why don't physicians test for HIV? A review of the US literature. AIDS 2007;21:1617-1624.

6. Deblonde J, De Koker P, Hamers FF, Fontaine J, Luchters S, Temmerman M. Barriers to HIV testing in Europe: a systematic review. European Journal of Public Health 2010 doi:10.1093/eurpub/ckp231.

7. Deblonde J, Meulemans, H, Callens S, Luchters S, Temmerman M, Hamers FF. HIV testing in Europe: mapping policies. Manuscript submitted for publication.

8. de Cock KM, Johnson AM. From exceptionalism to normalization: a reappraisal of attitudes and practice around HIV testing. BMJ 1998; (316):290-293.

9. Kellerman KS, Herold J. Physician response to surveys. A review of the literature. American Journal of Preventive Medicine 2001;20:61-67.

10. Kellock DJ, Rogstad KE. Attitudes to HIV testing in general practice. International Journal of STD\&AIDS 1998;9:263-267. 
11. Koo DJ, Begier EM, Henn MH, Sepkowitz KA, Kellerman SE. HIV counseling and testing: less targeting, more testing. American Journal of Public Health 2006;96(6):962-964.

12. Marks G, Crepaz N, Janssen RS. Estimating sexual transmission of HIV from persons aware and unaware that they are infected with the virus in the USA. AIDS 2006;20:1447-1450.

13. Marks G, Crepaz N, Senterfitt JW, Janssen RS. Meta-analysis of high-risk sexual behavior in persons aware and unaware they are infected with HIV in the United States: implications for HIV prevention programs. Journal of Acquired Immune Deficiency Syndromes 2005;39:446-453.

14. Mounier-Jack S, Nielsen S, Coker RJ. HIV testing strategies across European countries. HIV Medicine 2008;9 (Suppl. 2):13-19.

15. Project "Assessment of HIV testing in Europe: from policy to effectiveness": http://www.icrh.org/projects/assessment-of-hiv-testing-in-europe-from-policy-toeffectiveness) Accessed on 24.06.2010.

16. Rogstad KE, Henton L. General practitioners and the National strategy on sexual health and HIV. International Journal of STD AIDS 2004;15:169-172.

17. Stokes $\mathrm{SH}, \mathrm{McMaster} \mathrm{P}$, Ismail KM. Acceptability of prenatal rapid point-of-care HIV testing in an area of low HIV prevalence in the UK. Archives of Disease in Child 2007;92:505-508.

18. UNAIDS. Report on the global AIDS epidemic, an annex. Available at: http://www.unaids.org/GlobalReport/Global_report.htm. Geneva: UNAIDS, 2010. 19. World Health Organization. Centralized information system for infectious diseases (CISID) 2009: http://data.euro.who.int/cisid/ Accessed on 19.11.2009 
20. WHO/UNAIDS. Guidance on provider-initiated HIV testing and counselling in health facilities. Geneva: WHO, 2007. Available at: http://www.unhcr.org/refworld/docid/467f952f2.html [accessed 30 August 2010].

21. WHO. Scaling up HIV testing and counseling in the WHO European Region as an essential component of efforts to achieve universal access to HIV prevention, treatment, care and support. Policy Framework. WHO, 2010. 
Table 1 . Response rates by group and country

\begin{tabular}{|l|l|l|l|l|l|}
\hline & Belgium & Estonia & Finland & Portugal & Total \\
\hline Societies & & & & \\
sample & 11 & 12 & 10 & 19 & 52 \\
respondents & 10 & 5 & 10 & 6 & 31 \\
response rate, \% & 91 & 42 & 100 & 32 & 62 \\
\hline $\begin{array}{l}\text { Clinics } \\
\text { sample }\end{array}$ & 30 & 37 & 6 & 18 & 91 \\
respondents & 16 & 15 & 6 & 18 & 55 \\
response rate, \% & 53 & 41 & 100 & 100 & 60 \\
\hline
\end{tabular}

${ }^{\mathrm{a}}$ health professional society presidents

${ }^{\mathrm{b}}$ head physicians and nurses of hospital outpatient clinics 
Table 2. Description of the respondents, by group and country ${ }^{\mathrm{a}}$, numbers (total \%)

\begin{tabular}{|c|c|c|c|c|c|c|c|c|c|c|}
\hline & Societ & y presid & ents & & & Clinic ce & re prov & iders & & \\
\hline & Belg & Est & Fin & Por & Total (\%) & Belg & Est & Fin & Por & Total (\%) \\
\hline (Total number) & (10) & (5) & (10) & (6) & (31) (100) & (16) & (15) & (6) & (18) & (55) (100) \\
\hline Physician & 6 & 4 & 6 & 5 & $21(67.7)$ & 12 & 11 & 2 & 11 & $36(65.5)$ \\
\hline Man & 7 & 2 & 2 & 5 & $16(51.6)$ & 11 & 5 & 4 & 9 & $29(52.7)$ \\
\hline Professional exp & & & & & & & & & & \\
\hline years & 10 & 5 & 9 & 3 & $29(87.1)$ & 9 & 3 & 3 & 12 & $27(49.1)$ \\
\hline Not worked witl & & & & & & & & & & \\
\hline patients & 2 & 1 & 5 & 1 & $11(29.0)$ & 3 & 1 & 0 & 0 & $4(7.3)$ \\
\hline
\end{tabular}

${ }^{\mathrm{a}}$ Belg=Belgium, Est=Estonia, Fin=Finland, Por=Portugal 
Table 3. Is HIV testing like any other disease test (own views), by group and country, numbers (total \%) ${ }^{\mathrm{a}}$

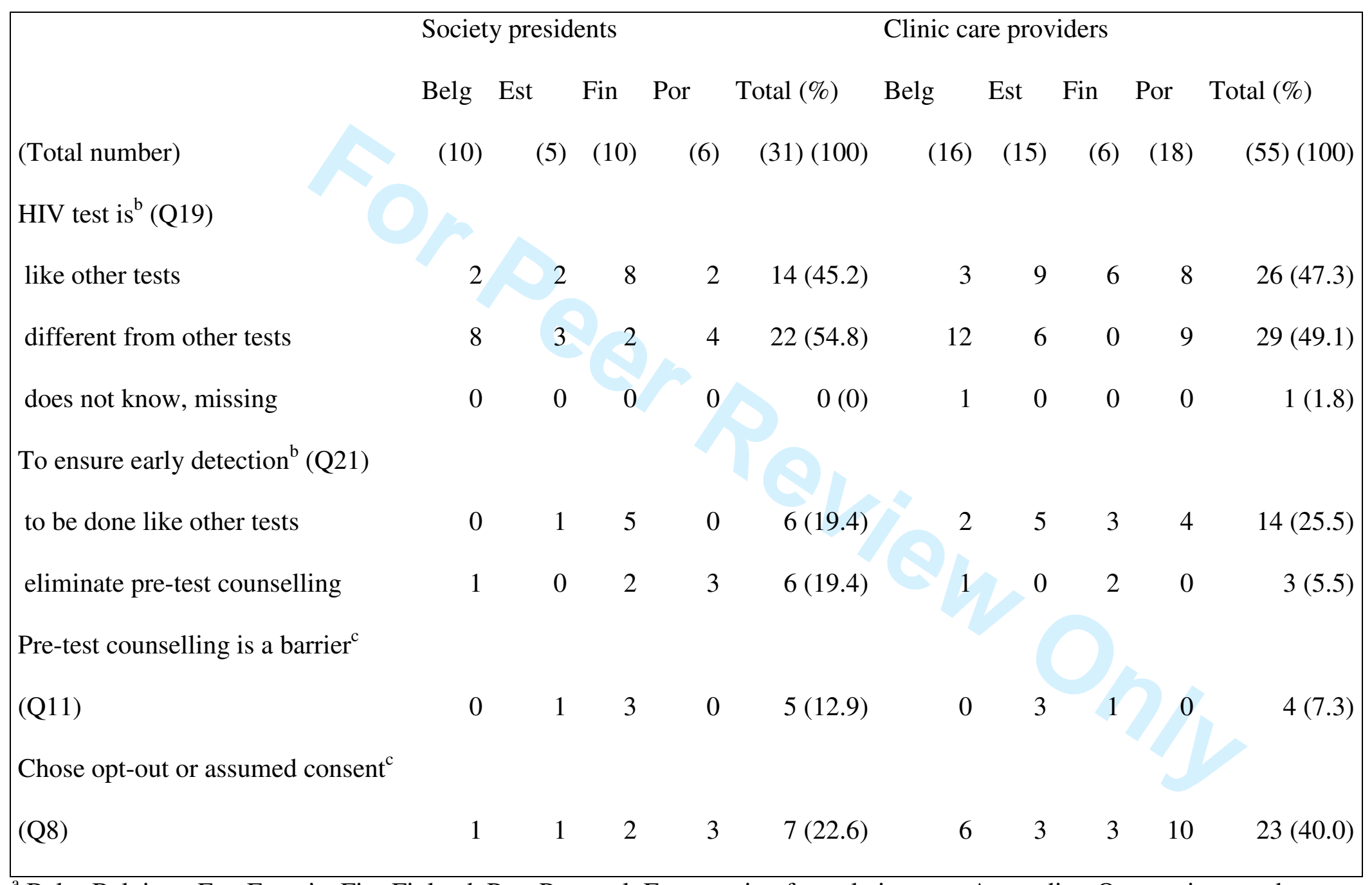

${ }^{\mathrm{a}}$ Belg=Belgium, Est=Estonia, Fin=Finland, Por=Portugal, For question formulations see Appendix ; Q=question number.

${ }^{\mathrm{b}}$ Own views rather than society or clinic views. 
${ }^{\mathrm{c}}$ Society view/ clinic practice. Opt-out=patients should be informed that HIV testing might be performed as part of their care, unless they explicitly decline. Assumed consent=consent should be assumed by seeking health care

$\mathrm{B}=$ Belgium, E=Estonia, F=Finland, Por=Portugal 
Table 4. One patient's or all (potential) patients interests, by group and country, numbers (total \%) ${ }^{\mathrm{a}}$

\begin{tabular}{|c|c|c|c|c|c|c|c|c|c|c|c|}
\hline \multirow{2}{*}{ (Total number) } & \multicolumn{6}{|c|}{ Society presidents } & \multicolumn{5}{|c|}{ Clinic care providers } \\
\hline & $\begin{array}{r}\text { Belg } \\
(10)\end{array}$ & $\begin{array}{l}\text { Est } \\
(5\end{array}$ & (5) & $\begin{array}{l}\text { Fin } \\
(10)\end{array}$ & $\begin{array}{l}\text { Por } \\
\qquad(6)\end{array}$ & $\begin{array}{l}\text { Total }(\%) \\
\qquad(31)(100)\end{array}$ & $\begin{array}{l}\text { Belg } \\
\qquad(16)\end{array}$ & $\begin{array}{l}\text { Est } \\
\text { (15) }\end{array}$ & $\begin{array}{l}\text { Fin } \\
\text { (6) }\end{array}$ & $\begin{array}{l}\text { Por } \\
\text { (18) }\end{array}$ & $\begin{array}{l}\text { Total }(\%) \\
\qquad(55)(100)\end{array}$ \\
\hline \multicolumn{12}{|c|}{ Most need for improvement (Q13) } \\
\hline prevention & 7 & & 3 & 5 & 2 & $17(54.8)$ & 11 & 11 & 5 & 10 & $37(67.3)$ \\
\hline access to HIV drugs & 0 & & 2 & 0 & 0 & $2(6.5)$ & 0 & 0 & 0 & 2 & $2(3.6)$ \\
\hline social, psychological support & 1 & & 4 & 3 & 3 & $11(35.5)$ & 2 & 7 & 0 & 12 & $21(38.2)$ \\
\hline \multicolumn{12}{|c|}{ HIV test should be required (Q20) } \\
\hline never & 1 & & 0 & 1 & 0 & $2(6.5)$ & 3 & 0 & 0 & 0 & $3(5.5)$ \\
\hline \multicolumn{12}{|l|}{ for visa to enter [own } \\
\hline country] & 1 & & 1 & 0 & 0 & $2(6.5)$ & 0 & 3 & 1 & 0 & $4(7.3)$ \\
\hline entering certain occupations & 1 & & 0 & 5 & 2 & $8(25.8)$ & 1 & 5 & 0 & 1 & $7(12.7)$ \\
\hline before undergoing surgery & 3 & & 2 & 7 & 0 & $12(38.7)$ & 0 & 4 & 1 & 2 & $7(12.7)$ \\
\hline in pregnancy & 8 & & 5 & 7 & 6 & $21(68.4)$ & 8 & 14 & 3 & 16 & $46(74.5)$ \\
\hline
\end{tabular}

${ }^{\mathrm{a}}$ Belg=Belgium, Est=Estonia, Fin=Finland, Por=Portugal. For question formulations see Appendix; Q=question number 
Table 5. Views on expansion of HIV testing, by group and country, numbers (total \%) ${ }^{\mathrm{a}}$

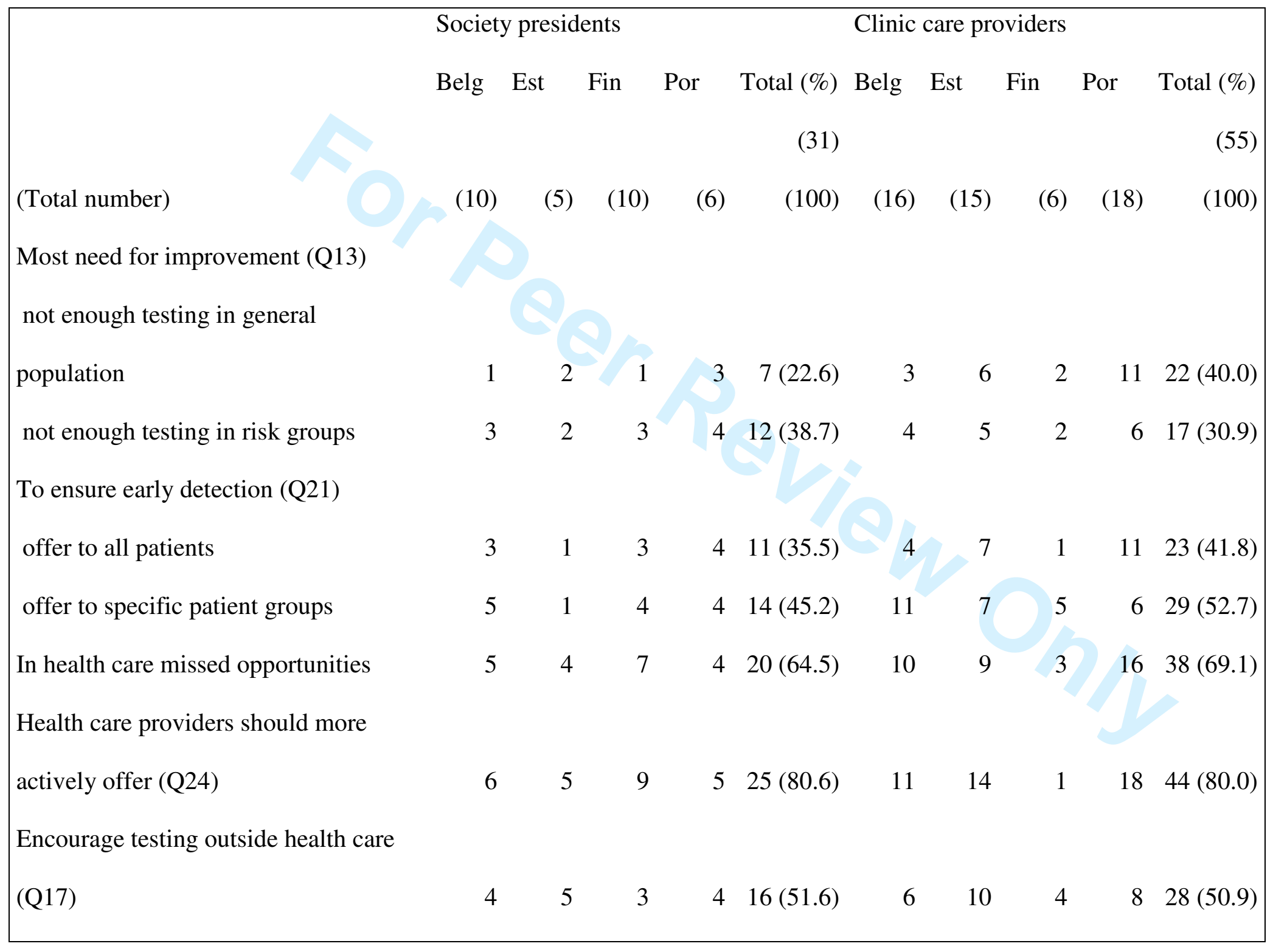




\begin{tabular}{lllllllllll|}
\hline Self-testing should be available (Q18) & 3 & 3 & 4 & 4 & $14(45.2)$ & 6 & 4 & 4 & 8 & $22(40.0)$ \\
\hline
\end{tabular}
${ }^{\mathrm{a}} \mathrm{B}=$ =Belgium, E=Estonia, F=Finland, Por=Portugal. For question formulations see Appendix; Q=question numbe


Appendix. Questions used in the paper

Q8 [13] Which of the following statements best describes the opinion of your society/organization with respect to offering HIV test to patients? [Which of the following statements best describes how the HIV test is offered to patients in your clinic/department?]

1. Patients should be informed that HIV testing might be performed as a part of their care, unless they explicitly decline. Assent is inferred unless the patient declines HIV testing. Some refer to this as opt-out testing./ Opt-out: patients are informed that HIV testing might be performed as a part of their care, unless they explicitly decline. Assent is inferred unless the patient declines HIV testing (presidents/providers)

2. Patients should be offered HIV testing, and if they agree to testing, they must provide explicit consent. Some refer to this as opt-in testing./ Opt-in: patients are offered HIV testing, and if they agree to testing, they must provide explicit consent (presidents/providers)

3. Consent should be assumed by seeking health care.

4. Our society/organisation has not discussed this topic./ Do not know (presidents/providers)

5. Don't know (as option 4 in providers questionnaire)

Q9 [23] Do you think that there are missed opportunities in health care settings to diagnose HIV infection?

1. No

2. Yes

3. Not sure

4. Do not know

Q10 [24] Do you think that health care providers should offer HIV testing more actively? 
1. Yes

2. No

3. Do not know

Q11 [25] What do you consider, if any, the main barriers for health care providers to offer HIV testing? (Check one or more answers and indicate ranking order, starting from 1 as being the most important barrier)

- Lack of time

- Lack of resources (staff, materials,...).

- Language barrier with the patient

- Reluctant to discuss sensitive topics (sexual behavior, drugs,.).

- Reluctant to speak about HIV with a patient

- Afraid of stigmatizing some populations by targeting them for testing

- Pre-test counseling is a barrier

- Lack of knowledge of testing guidelines

- Difficulty to identify people at increased risk

- HIV is not a priority in the country

- Testing not covered by health insurance or equivalent

- Other, specify

- They do not have any barriers for offering an HIV test

- Don't know

Q13 [31] What are the less performing areas in the HIV health care system and in most need for further improvement in your [country]? [Check up to three answers]

1. Prevention of epidemic: information \& education, condoms, clean needles etc.

2. Not enough testing in general population 
4. Too little testing in risk groups

5. Referral system for HIV+ patients

6. Access to specific HIV drug treatment

7. Quality of HIV medical care

8. Extent of social and psychological support

9. Payment system for HIV health care

10. Risk reduction programs, e.g. needle exchange programs

11. Other, specify

12. Don't know

Q17 [32] Should HIV testing be encouraged outside health care, for example by outreach programmes?

1. Yes

2. No

3. Do not know

Q18 [34] Should self-testing be (more) available in [country]?

1. Yes

2. No

3. Do not know

Q19 [28] Which comes closer to your opinion?

1. HIV testing should be treated just like routine screening for any other disease, and should be included as part of regular check-ups

2. HIV testing is different from screening for other diseases, and should require special procedures, such as pre-test counseling and explicit informed consent to perform the test

3. Don't know 
Q20 [33] In your opinion, should HIV testing be required in any of the following cases?

1. For obtaining visa to arrive [the country]

2. To enter certain profession/ occupation, specify ...

3. To enter a certain school, specify ...

4. When returning from military operation abroad

5. Before undergoing surgery

6. Pregnancy

7. Other, specify

8. Never

9. Don't know

Q21 [35] In your opinion, what are the best ways to ensure that HIV infected people are tested early? [Check up to three answers]

1. Offering the HIV test to all patients in health care settings

2. Offering the HIV test to specific groups of patients

3. HIV tests should be done routinely like any other test

4. Eliminating the requirement of pre-test counseling

5. Providing training for health care providers in HIV

6. Ensuring adequate treatment and care

7. Increasing voluntary testing and counseling sites

8. Increasing the number of anonymous testing sites

9. Licensing home testing

10. Effective promotion and public information campaigns on HIV testing 11. Providing more information and education on HIV and HIV treatment 
12. To change laws to abolish discrimination based on HIV status

13. Reducing barriers to accessing health care

14. Other, specify

15. Don't know

Numbering refers to the society presidents' questionnaire. If the formulation for clinic providers was different, it is indicated in the B-option.

In questions 10, 17 and 18 the yes-no options in the clinic provider questionnaire were in an opposite order. 